\title{
Effects of policosanol on the recovery of ischemic stroke: a randomized controlled study
}

\author{
Dr. Javier Sánchez ${ }^{1}$, Dr. Lilia Fernández ${ }^{2}$, Dr. José Illnait ${ }^{2}$, Dr. María de \\ Lourdes Arruzazabala ${ }^{2}$, Dr. Vivian Molina², Dr. Rosa Mas², Dr. Sarahí \\ Mendoza $^{2}$, Dr. Daisy Carbajal ${ }^{2}$, BsC. Meilis Mesa ${ }^{3}$, Dr. Julio Fernández ${ }^{2}$ \\ ${ }^{1}$ Institute of Neurology and Neurosurgery, Havana City, Cuba \\ ${ }^{2}$ Natural Products Center, National Center for Scientific Research, Havana City, Cuba \\ ${ }^{3}$ Surgical Medical Research Centre, Havana City, Cuba
}

\begin{abstract}
Background. Antiplatelet therapy lowers the risk of recurrent stroke. Policosanol, a mixture of 8 high molecular weight sugar cane wax alcohols, has shown to reduce platelet aggregation.

Objectives. To investigate whether the therapy with policosanol plus aspirin (AS) could improve the neurological outcome as compared to placebo + AS in patients with a recent ischemic stroke.

Methods. Ninety-two (92) patients with a modified Rankin Scale score (mRSs) $\geq 2-\leq 4$ after suffering an ischemic stroke within 30 days before enrollment were randomized to placebo or policosanol (20 mg/day) + AS $(125 \mathrm{mg} /$ day) (pla + AS or poli + AS) for 24 weeks. The primary efficacy variable was to obtain a better stroke outcome (mRSs $\leq 1)$ as compared to pla +AS. Reduction of platelet aggregation was a secondary variable.

Results. After 12 and 24 weeks on therapy, the rates of patients treated with poli + AS (10/46, 21.7\% and 32/46, $69.6 \%$, respectively) who achieved mRSs $\leq 1$ were significantly ( $\mathrm{p}<0.01$ and $\mathrm{p}<0.0001$, respectively) greater than those treated with pla + AS (0/46, $0.0 \%$ and 7/46, $15.2 \%$, respectively). Poli + AS treatment given for 6 weeks reduced significantly $(\mathrm{p}<0.00001$ vs baseline, $\mathrm{p}<0.01 \mathrm{vs} \mathrm{pla}+\mathrm{AS})$ the mean mRSs value $(24.1 \%)$, and this effect improved thereafter, so that it was reduced by $31.0 \%$ and $55.2 \%$ after 12 and 24 weeks on therapy, respectively. Poli + AS treatment also reduced significantly arachidonic acid- and adenosine diphosphateinduced platelet aggregation by $41.0 \%$ and $24.8 \%$, respectively. Treatments were well tolerated. There were not withdrawals due to adverse experiences.

Conclusions. In patients with recent ischemic stroke, poli + AS treatment improved the neurological recovery and decreased platelet aggregation as compared to pla + AS.
\end{abstract}

Keywords: Antiplatelet drugs, Aspirin, Ischemic stroke, Policosanol, Rankin-modified scale, Stroke

\section{INTRODUCTION}

Stroke results from the sudden interruption of blood flow to a brain region that impairs the energy supply to the central nervous system. Strokes can be ischemic (atherothrombotic, embolic, lacunar, hemodynamic) (75-80\% of all strokes) or hemorrhagic (about 20\%) [1]. Hypoxia is considered as the main cause of central nervous system damage in stroke. The ischemic gradient in cerebral ischemia involves the core (central ischemic zone) and the penumbra (peripheral zones). Both neurons and glial cells have functional changes in the penumbra, neurons being more vulnerable to hypoxia because they depend on the oxidative metabolism of glucose for energy [2]. Stroke involves complex events, like the disturbance of blood-brain barrier permeability, cell ion unbalance, energy failure, acidosis, elevated intracellular calcium, excitotoxicity and free radical-mediated toxicity, which can lead to ischemic necrosis with loss of calcium and glutamate homeostasis $[1,2]$.

Stroke is the third cause of adult mortality and the first one of disability worldwide, including Cuba $[3,4]$. Patients with recent ischemic stroke or transient ischemic attack (TIA) face a high risk of recurrent stroke and coronary events, and control of risk factors such as hypertension, diabetes, hypercholesterolemia, cigarette smoking and obesity are key measures to stroke management [4].

Several studies and meta-analyses support the merits of antiplatelet drugs in stroke prevention by lowering platelet function, which reduces thrombotic complications of atherosclerosis [5-8]. Aspirin (AS) remains the gold standard of antiplatelet therapy for stroke prevention, whereas extended release dypiridamole + AS has yielded the best results among combination therapy schemes [5-8].

Policosanol, a mixture of 8 high molecular weight sugarcane wax alcohols, has reduced platelet aggregation in 
experimental and clinical studies [9-13]. Also, policosanol has shown protective effects in experimental brain ischemia models, and to increase the antiplatelet/antithrombotic effects of AS [14,15], and long-term administered prevented the progression of carotid-vertebral atherosclerosis in humans [16].

Keeping in mind these results, two long-term open studies explored the effects of therapy with policosanol + AS administered during hospital admission and for long-term (4 and 5 years) to patients who had had suffered ischemic strokes and found that such therapy was associated to very good results on neurological outcomes. Their open and uncontrolled designs, however, had methodological limitations for strong conclusions $[17,18]$.

In light of these issues, this study investigated whether the therapy with policosanol $20 \mathrm{mg} / \mathrm{day}+\mathrm{AS}$ $125 \mathrm{mg} /$ day could improve the neurological outcome and reduce platelet aggregation in patients who had suffered a recent ischemic stroke as compared to placebo + AS $125 \mathrm{mg} / \mathrm{day}$ (pla + AS).

\section{MATERIALS AND METHOD}

\subsection{Study design}

This study was conducted in the Institute of Neurology and Neurosurgery (Havana City, Cuba) after obtain the approval of the independent Ethics Committee. The study enrolled patients who had had recent ischemic stroke within the 30 days before recruitment and gave their informed written consent (Visit 1). All participants underwent clinical history and full clinical examination. As part of healthy life style measures, we advised patients to start or continue on a low-sodium and low fat diet and strongly recommend stop smoking.

Eligible patients were randomized to poli + AS or pla + AS (visit 2) for 24 weeks and attended to control visits at $6,12,18$ and 24 weeks on treatment (visits $3-6$ ). Patients underwent general examination and neurological assessment at each visit, laboratory analyses at baseline and after 12 and 24 weeks on therapy, meanwhile we controlled drug compliance and adverse experiences (AE) from visits 3 to 6 .

\subsection{Study patients}

Enrolled patients were ambulatory men and women over 40 years of age who had had an ischemic stroke (diagnosed by a neurologist) within the 30 days prior to enrollment.

The study protocol defined stroke as the occurrence of focal clinical signs of central nervous system dysfunction of vascular origin that lasted for at least 24 hours. Ischemic stroke was confirmed through clinical assessment and computerized axial tomography performed within the following 48 hours after stroke onset.

Eligible patients were those who fulfilled the enrollment criteria and had a modified Rankin Scale score (mRSs) of 2, 3 or 4 [19]. The exclusion criteria included suspected or confirmed hemorrhagic stroke, atrial fibrillation, other cardiac sources of embolism, subarachnoid haemorrhage, diastolic hypertension $\geq 110 \mathrm{~mm} \mathrm{Hg}$, cardiac valve diseases, history of myocardial infarction, instable angina or revascularization surgery within the 6 months prior to the trial and previous consumption of policosanol.

\subsection{Treatment}

Patients consumed policosanol (20 mg/day) + AS (125 mg/day) or placebo + AS (125 mg/day) once daily with the breakfast for 24 weeks. Keeping in mind that randomized controlled trials support the use of daily doses of AS $(75-150 \mathrm{mg})$ for the prevention of vascular events in high-risk patients we used a dose of 125 $\mathrm{mg} /$ day [4-8].

Good or very good treatment compliance, assessed through counts of remainder tablets and patient's interviews, was to consume at least $85 \%$ or $90 \%$, respectively, of scheduled tablets per period.

The consumption of other antiplatelet or lipid-lowering drugs was prohibited during the study. Patients who were taking lipid-modifying drugs had to stop these medications 30 days before to enrollment.

\subsection{Study outcomes}

The hypothesis of the study was that poli + AS treatment would improve the stroke neurological outcomes among patients with recent ischemic stroke. The primary efficacy variable was to obtain a significant increase of patients with a favourable stroke outcome (mRSs $\leq 1)$ at 24 weeks as compared to pla +AS.

Secondary efficacy variables were to obtain significant reductions of platelet aggregation to arachidonic acid (AA) and to adenosine diphosphate (ADP). Effects on lipid profile values were collateral efficacy variables.

\subsection{Laboratory analyses}

Venous blood samples were taken following a fasting of 12 hours.

\subsubsection{Platelet aggregation assay}

Aliquots of blood samples, placed into tubes containing 3.8\% sodium citrate, were centrifuged at 1000 
rpm for 10 minutes. Then, we took the layer of platelet rich plasma (PRP), centrifuged the remaining blood sample for another $10 \mathrm{~min}$ at $2500 \mathrm{rpm}$ and removed the thin layer constituting the platelet poor plasma (PPP).

We assessed the platelet aggregation responses to AA $(3 \mathrm{mmol} / \mathrm{L})$ and ADP $(2 \mathrm{mmol} / \mathrm{L})$ according to the light transmission method [20], using a dual-channel optical aggregometer. We calibrated the equipment for maximum (100\%) and minimum (0\%) light transmission using $350 \mu \mathrm{L}$ of PPP and PRP, respectively, from each subject at each point. The PRP was then incubated at $37{ }^{\circ} \mathrm{C}$ for 2 minutes and assessed the extent of platelet aggregation as the percent of maximal light transmission reached within 5 minutes of the addition of each agonist evaluated at each time.

\subsubsection{Lipid profile and blood safety indicators}

Serum levels of total cholesterol, triglycerides, high-density lipoprotein-cholesterol (HDL-C) and blood biochemistry indicators were determined by enzymatic methods using reagent kits (Roche, Basel, Switzerland) in a Hitachi 719 autoanalyzer (Tokyo, Japan) of the clinical laboratory of the Medical Surgical Research Centre. LDL-C values were calculated using Friedewald equation [21].

\subsection{Safety and tolerability assessment}

Safety and tolerability indicators included laboratory and physical examination data, and AE reports. Study protocol defined AE as any undesirable experience, absent at hospital discharge or worsened thereafter, happening in a patient, independently if it could be or not related with the therapy and were classified as mild, moderate or serious according to their intensity. Mild AE should not require stopping of study medications or specific treatment of the $\mathrm{AE}$, moderate $\mathrm{AE}$ should require the withdrawal of study medications and/or treatment of the $\mathrm{AE}$, while serious $\mathrm{AE}$ should lead to patient hospitalization and/or to death.

\subsection{Statistical Analysis}

The study was designed to have a statistical power of 80 percent to detect a reduction of $20 \%$ in the frequency of poli + AS-treated cases with a favourable outcome as compared to the pla + AS group, with a significance level of $p<0.05$. Given the specified statistical power, we needed 90 eligible patients, and assuming a total dropout rate of 10 percent, we enrolled 99 patients.

We analyzed the data on an intention-to-treat basis, including those of all patients who underwent randomization. Continuous values were analyzed with the $t$ test for paired (within group comparisons) and independent (between group comparisons) samples, and the Bonferroni's test was used to adjust significances from repeat comparisons [22]. Categorical data were compared with the Fisher Exact Probability test. All p values were two-sided.

\subsection{Population characteristics}

\section{RESULTS}

Of 100 screened patients, 92 (mean age: 66 years) (46 men, 46 women) fulfilled the inclusion criteria and underwent randomization. Ninety of these 92 patients $(97.8 \%)$ completed the trial. There were two withdrawals, none due to AE: 1 due to unwillingness to follow (pla + AS), 1 due to travel abroad (poli + AS).

Both groups showed comparable baseline characteristics, so that they were homogeneous for comparisons (Table 1). The most frequent (>30\%) risk factors at baseline were lifestyle related: consumption of salt-rich food (96.7\%), sedentary life (95.6\%), hypertension (94.6\%), overweight plus obesity $(64.1 \%)$ and smoking $(45.7 \%)$.

The rate of use of concomitant therapy was well balanced in the two groups and high $(82.6 \%)$. The most frequent concomitant drugs were the angiotensin converting enzyme inhibitors (ACEI) (72.8\%), while the consumption of other drugs was actually low $(<5 \%)$.

\subsection{Effects on study outcomes}

During the study drug compliance was very good $(\geq 90 \%)$ and similar in both groups. No patient experienced recurrent cerebrovascular event or any other major vascular event during the study.

At randomization the distribution of patients into the different mRSs values (2,3 and 4) was similar in both groups (Table 2). After 12 and 24 weeks on therapy, the frequencies of poli + AS patients (10/46, 21.7\% and $32 / 46,69.6 \%$, respectively) who achieved $\mathrm{mRSs} \leq 1$ were significantly ( $\mathrm{p}<0.01$ and $\mathrm{p}<0.0001$, respectively) greater than in the pla + AS group (0/46, $0.0 \%$ and $7 / 46,15.2 \%$, respectively). At study completion, $3 / 46(6.5 \%)$ poli + AS, 20/46 (43.5\%) pla + AS patients $(\mathrm{p}<0.001)$ had $\mathrm{mRSs}$ values $\geq 3$.

At week 6 on treatment the mean mRSs values had decreased $(24.1 \%)$ significantly $(\mathrm{p}<0.00001$ vs baseline, $\mathrm{p}<0.01 \mathrm{vs}$ pla + AS) with poli + AS, and this treatment effect did not wear off, but improved thereafter, so that significant reductions of $31.0 \%$ and $55.2 \%$ ) were found after 12 and 24 weeks on therapy. At study completion, the net reduction versus pla + AS was $37.3 \%$. Meanwhile, a significant and moderate decrease of 
mRSs occurred in the pla + AS group (17.9\% reduction vs baseline at study completion).

The mean $(\mathrm{X} \pm \mathrm{SME})$ values of platelet aggregation were similar in the two groups at baseline (Table 4). Twelve weeks after randomization, poli $+\mathrm{AS}$, not pla $+\mathrm{AS}$, had decreased the mean percent values of AAinduced platelet aggregation from 43.2 to 30.1 (a reduction of $30.3 \%, \mathrm{p}<0.05$ vs baseline). At the end of the study the mean percent values of AA-induced platelet aggregation had lowered ( $\mathrm{p}<0.01)$ to 25.5 (a reduction of 41.0\%). Changes in pla + AS group were not significant (-3.8\%). Changes in ADP-induced platelet aggregation exhibited a similar, but less marked trend. At week 12 , poli + AS, not pla + AS, had reduced $(\mathrm{p}<0.05$ vs baseline) platelet aggregation values by $19.0 \%$, while at study completion the mean decrease was $24.8 \%$ $(\mathrm{p}<0.05$ vs baseline).

The two groups had similar mean lipid profile levels at baseline (Table 5). Poli + AS treatment, not pla + AS, decreased significantly $(\mathrm{p}<0.01$ vs baseline, $\mathrm{p}<0.05 \mathrm{vs}$ pla + AS) the mean LDL-C values after $12(16.7 \%)$ and $24(25.5 \%)$ weeks of randomization. Therapy with poli + AS also decreased significantly $(\mathrm{p}<0.001)$ total cholesterol $(12.4 \%)$ and increased ( $\mathrm{p}<0.01$ vs baseline, $\mathrm{p}<0.05$ vs pla + AS) HDL-C values $(10.5 \%)$.

\subsection{Safety and tolerability}

Treatments were safe and well tolerated. No patient discontinued from the study due to AE. Treatments did not impair safety physical or blood indicators and individual values were not out of normal limits. Systolic blood pressure values, however, lowered significantly $(\mathrm{p}<0.01)$ in the poli + AS group as compared to pla + AS (Table 6). In addition, final values of ALT in poli + AS were lower $(\mathrm{p}<0.05)$ than in pla + AS (Table 7).

Five patients ( 3 poli + AS, 2 pla + AS) experienced mild AE (3 insomnia, 2 heartburn), without significant differences between the groups.

\section{DISCUSSION}

This study, the first double-blind, randomized and controlled trial of the effects of policosanol on post stroke recovery, demonstrated that treatment with poli + AS significantly improved stroke functional outcomes in patients who had had a recent ( $\leq 30$ days) moderate to severe ischemic stroke. These results are consistent with previous data of the effects of policosanol in patients with ischemic stroke obtained in two open, uncontrolled, long-term studies, whose designs had limitations for strong conclusions [17,18]. Benefits of poli + AS treatment on platelet aggregation were also seen.

The strengths of this study include that it was randomized, double-blinded and controlled with a group that received AS, the conventional therapy used in our country to manage ischemic stroke, plus placebo.

Keeping in mind that both groups were homogeneous at baseline, the effects here observed can be attributable to the combination therapy and specifically to the addition of policosanol to the therapeutic scheme. In addition, the fact that 90/92 (97.8\%) randomized patients concluded the study and that treatment compliance was comparable in both groups supports the validity of the present results. Also, we restricted eligibility criteria to have mRSs from 2 to 4 in order to reduce the influence of the variability of stroke severity on the results.

Baseline characteristics of study population match well with stroke epidemiological data. The mean age of patients, and the high frequency of risk factors for stroke, including salt consumption, sedentary life, hypertension, overweight \& obesity, hypercholesterolemia and smoking were consistent with those reported [4]. In addition to AS and study treatments (policosanol or placebo), the most frequent concomitant medications were ACEI, well balanced in both groups, with few consumption $(<5 \%)$ of other drugs, so that we discard the potential influence of concomitant therapy to the present results.

Stroke scales, developed for objectively assessing the degree of patient recovery and the need of standardization for comparing the results across stroke studies, have been used as the primary or secondary efficacy variables for evaluating the neurological improvement in several stroke studies [23]. We assessed the effects on stroke outcome by using the validated mRSs [19], a reliable tool that reflects the global disability of the patients and that have been extensively used as a clinical variable to assess the recovery after stroke [24,25]. Our results support the usefulness of poli + AS therapy in the neurological recovery post-ischemic stroke assessed through the mRSs, the primary efficacy variable, over pla + AS. First, the rate of patients treated with poli + AS who achieved good stroke outcomes (32/46, 69.6\%) was significantly higher than in pla + AS (7/46, $15.2 \%$ ) in $>20 \%$ (pre-specified efficacy criterion) despite we selected a restrictive cut-off limit for qualifying a good stroke outcome (mRSs $\leq 1)$. Second, the significant reduction of the mean mRSs values from 6 weeks after randomization to study completion. After 12 and 24 weeks on treatment, the net differences of mRSs versus pla + AS were $23.9 \%$ and $37.3 \%$, respectively. Keeping in mind the neurological improvement obtained at 12 weeks after stroke in the NINDS rt-PA study, a 11-13\% reduction of mRSs, despite the patients were treated as soon as within the first hours of acute stroke [24], we should consider the present results of clinical relevance. It should be noted that a moderate and significant decrease of mRSs (17.9\% at the end of the study) was seen in the pla + AS group, a logical result considering that all patients received first-line conventional post-stroke therapy (life style changes + AS) and the time elapsed from stroke debut.

The effects of poli + ASA treatment on platelet aggregation were also positive. At randomization a 
relatively high frequency of patients $(36 / 92,39.1 \%)$ had very low values $(\leq 10 \%)$ of platelet aggregation to AA ( $3 \mathrm{mmol} / \mathrm{L}$ ), a good response to the antiplatelet effects of AS, since at that moment all patients already were under AS treatment. These results are consistent with AS-induced irreversible inhibition of cyclooxygenase-1 (COX-1) activity in platelets and megakaryocytes that blocks the formation of thromboxane $\mathrm{A}_{2}$ (potent vasoconstrictor and platelet aggregant) [26]. Since platelets are unable to regenerate COX, the immediate antithrombotic effect of AS remains for the platelet lifespan (8-10 days). When given as a single oral dose, AS $(160 \mathrm{mg})$ maximally inhibits platelet function within 30 minutes. Repeat doses have a cumulative effect and platelet $\mathrm{TXA}_{2}$ formation and platelet aggregation are maximally inhibited (>95\%) after $4-5$ days [26,27]. Then, the lack of significant reduction of platelet aggregation in the pla + AS group here found is reasonable, since all patients had at least one week on AS therapy at randomization. After 12 and 24 weeks on treatment AA-induced platelet aggregation decreased significantly by $30.3 \%$ and $41.0 \%$, respectively, with poli + AS and unchanged with pla + AS. These results support that policosanol added to AS therapy enhances the antiplatelet response to AA-induced platelet aggregation, a variable on which AS produces noticeable inhibitory effects.

ADP-induced platelet aggregation decreased moderately $(<30 \%)$ with poli + AS $(19.0 \%$ and $24.9 \%$ reductions at weeks 12 and 24, respectively). AS alone has a weak effect on ADP-induced platelet aggregation, consistent with the fact that its antiplatelet effect does not involve the antagonism of platelet ADP receptors [26]. Then, the superior efficacy of poli + AS should be attributable to the inclusion of policosanol in the therapeutic scheme.

The antiplatelet effects here seen, therefore, could be responsible, at least partly, of the benefits of poli + AS therapy on stroke outcomes over the conventional AS therapy.

No demonstration of the mechanisms of the antiplatelet effects of policosanol is available, but they involve a simultaneous decrease of $\mathrm{TxA}_{2}$ and increase of prostacyclin concentrations rather than an inhibition of $\mathrm{COX}_{2}$ activity [13,15], being logical to expect a greater antiplatelet efficacy of poli + AS over pla + AS therapy. We also found that poli + AS reduced low-density lipoprotein-cholesterol (LDL-C) by $16.7 \%$ (week 12) and $25.5 \%$ (week 24) as compared to pla + AS, and that also had benefits on total cholesterol and HDL-C. Although some trials have failed to find lipid lowering effects of other policosanol tablets [27-29], the cholesterollowering effects here seen are consistent with previous experimental [30-34] and clinical [35-38] data of policosanol. Since statins may improve outcomes in acute ischemic stroke [39,40], these effects of poli + AS treatment could have contributed to the neurological recovery of study patients.

There were not recurrent strokes or transient ischemic attack among study participants, a result particularly good since the highest probability of recurrent events occurs within the first 12 weeks post-stroke [4]. This result confirms the usefulness of conventional therapy with AS in patients who had experienced an ischemic stroke.

Consistent with previous studies in stroke patients $[17,18]$, poli + AS treatment was safe and well tolerated. No patient discontinued the study due to $\mathrm{AE}$, the frequency of $\mathrm{AE}$ was low, and all $\mathrm{AE}$ were mild. Systolic blood pressure decreased significantly with poli + AS as compared to pla + AS, consistent with some previous data $[18,35]$. Nevertheless, since no patient had hypotension values and there was a high frequency of hypertensive patients in the study, this effect could be potentially beneficial, rather than adverse, for stroke recovery.

\section{CONCLUSIONS}

Poli + AS treatment improved the neurological recovery as compared to pla + AS (conventional therapy), and decreased platelet aggregation in patients with recent ischemic stroke, which suggests the usefulness of administering this therapy as soon as after hospital discharge due to a recent ischemic stroke, but further studies should confirm the present results.

\section{ACKNOWLEDGEMENTS}

A research grant of the West Havana Scientific Pole supported this study conduction. No financial interests or other conflicts influence the conclusions or outcome of this study report. No author has received financial support from a commercial source.

\section{REFERENCES}

[1] P. Amarenco , J. Bogousslavsky, L. Caplan, G. Donnan, and M. Hennerici, Classification of stroke subtypes, Cerebrovasc Dis, 27, 2009, 493-501.

[2] D. Amantea, G. Nappi, G. Bernardi, G. Bagetta, and M. Corasaniti, Post-ischemic brain damage: pathophysiology and role of inflammatory mediators, FEBS J, 276, 2009, 13-26.

[3] Public Health Ministry. Statistical Annual Report 2010, Havana City, Cuba. http://www.sld.cu.scielo.php.script

[4] R.L. Sacco, R. Adams, G. Alberts, M.J. Alberts, O. Benavente, K. Furie, et al, Guidelines for 
prevention of stroke in patients with ischemic stroke or transient ischemic attack: a statement for healthcare professionals from the American Heart Association/American Stroke Association Council on Stroke: co-sponsored by the Council on Cardiovascular Radiology and Intervention: the American Academy of Neurology affirms the value of this guideline, Stroke, 37, 2006, 577-617.

[5] Antithrombotic Trialists' Collaboration, Collaborative meta-analysis of randomised trials of antiplatelet therapy for prevention of death, myocardial infarction and stroke in high/risk patients, BMJ, 324, 2000, 71-86.

[6] M. Levi, Thromboprophylaxis for cerebrovascular disorders: acetylsalicylic acid remains the cornerstone, Ned Tijdschr Geneeskd, 152, 2008, 423-425.

[7] D.J. Likosky, K. Lee, D.M. Brown, A. Amin, D.D Dressler, D. Krakow, et al, Evidence-based medicine: Review of guidelines and trials in the prevention of secondary stroke, J Hosp Med, 3(S4), 2008, S6-S19.

[8] C. Patrono, and B. Rocca B, Aspirin: promise and resistance in the new millennium, Arterioscler Thromb Vasc Biol, 28, 2008, s25-32.

[9] M.L. Arruzazabala, D. Carbajal, R. Más, M. García, and V. Fraga, Effects of policosanol on platelet aggregation in rats, Thromb Res, 69, 1992, 321-327.

[10] A. Scazziota, S. Pons, and R. Altman, Efecto del policosanol sobre la función de las plaquetas en voluntarios sanos, Rev Iberoam Trombo Hemost, 9, 1996, 58-62.

[11] M.L. Arruzazabala, S. Valdés, R. Mas, D. Carbajal, L. Fernández, et al, Comparative study of policosanol, aspirin and the combination of policosanol-aspirin on platelet aggregation in healthy volunteers, Pharmacol Res, 36, 1997, 293-297.

[12] D. Carbajal, M.L. Arruzazabala, S. Valdés, and R. Mas, Effect of policosanol on platelet aggregation and serum levels of arachidonic acid metabolites in healthy volunteers, Prostagl Leukotr Essent Fatty Acids, 58, 1998, 61-64.

[13] G. Castaño, R. Más, M.L. Arruzazabala, M. Noa, J. Illnait, J.C. Fernández, et al, Effects of policosanol, pravastatin on lipid profile, platelet aggregation, endothelemia in older hypercholesterolemic patients, Int J Clin Pharm Res, 19, 1999, 105-116.

[14] M.L. Arruzazabala, D. Carbajal, V. Molina, S. Valdés, and R. Mas, Effect of policosanol on cerebral ischemia in Mongolian gerbils: Role of prostacyclin and thromboxane A2, Prostag Leuk and Ess Fatty Acids, 49, 1993, 695-697.

[15] V. Molina, M.L. Arruzazabala, D. Carbajal, S. Valdés, M. Noa M, R. Más, et al, Effect of policosanol on cerebral ischemia in Mongolian gerbils, Brazil J Med Biol Res, 32, 1999, 1269-1276.

[16] J, Batista, R. Stusser, M. Penichet, and E. Uguet, Doppler-ultrasound pilot study of the effects of longterm policosanol therapy on carotid-vertebral atherosclerosis, Curr Ther Res, 56, 1995, 906-914.

[17] L. Ortega, J. Sánchez J, R. Mas, L. Fernandez, S. Mendoza, R. Gamez, et al, Effects of policosanol on patients with ischemic stroke. A pilot open study, J Med Food, 9, 2006, 378-385.

[18] J. Sánchez, R. Mas, S. Mendoza, J.C. Fernández, and D. Ruiz, Effects of policosanol on patients with ischemic stroke and previous transient ischemic attack: A long-term follow-up, Rev CENIC Cien Biol, 41, 2010, 23-29.

[19] J. Rankin, Cerebral vascular accidents in patients over the age of 60. II. Prognosis, Scott Med J, 2, 1957, 200-215.

[20] G. Born, Aggregation of blood platelets by adenosine diphosphate and its reversal, Nature, 194, 1962, $927-930$.

[21] W.T. Friedewald, R.I. Levy, and D.S. Fredrickson, Estimation of the concemtration of lowdensity lipoprotein cholesterol in plasma, without use of the preparative ultracentrifuge, Clin Chem, 18, 1972, 499-502.

[22] P.C. O'Brien, and M.A. Shampo, Statistical considerations for performing multiple tests in a single experiment. Comparing two therapies with respect to several endpoints, Mayo Clin Proc, 63, 1988, 1140-1143.

[23] C. Bushnell, D. Jhonston, and L. Goldstein, Retrospective assessment of initial stroke severity. Comparison of the NIH stroke scale and the Canadian neurological scale, Stroke, 32, 2001, 656-658.

[24] The National Institute for Neurological Desorders and Stroke rt-PA Stroke Study Group, N Engl J Med, $333,1995,1581-1587$.

[25] I. Miedema , M. Uyttenboogaart , K. Koopman , J. De Keyser, and G.J. Luijckx, Statin use and functional outcome after tissue plasminogen activator treatment in acute ischaemic stroke, Cerebrovasc Dis, 29, 2010, 263-267.

[26] E.H. Awtry, and J. Loscalzo, Aspirin, Circulation, 101, 2000, 1206-1218.

[27] H.K. Berthold, S. Unverdoben, R. Degenhardt, M. Bulitta, and I. Gouni-Berthold, Effect of policosanol on lipid levels among patients with hypercholesterolemia or combined hyoperlipidemia: a randomized 
Effects of policosanol on the recovery of ischemic stroke: a randomized controlled study

controlled trial, JAMA, 295, 2006, 2262 -2269

[28] M.F. Dulin, L.F. Hatcher, H.C. Sasser, and T.A. Barringer, Policosanol is ineffective in the treatment of hypercholesterolemia: a randomized controlled trial, Am J Clin Nutr, 84, 2006, 1543 - 1548.

[29] F. Francini, D. Beltramolli D, S. Dall'acqua, and F. Brocadello, Effect of sugar cane policosanol on lipid profile in primary hypercholesterolemia, Phytother Res, 22, 2008, 318 - 322.

[30] I. Setnikar , P. Senin , and L.C. Rovati, Antiatherosclerotic efficacy of policosanol, red yeast rice extract and astaxanthin in the rabbit, Arzneimittelforschung, 55, 2005, 312-317.

[31] C.H. Ng, K.Y. Leung, Y. Huang, and Z.Y. Chen, Policosanol has no antioxidant activity in human lowdensity lipoprotein but increases excretion of bile acids in hamsters, J Agric Food Chem, 53, 2005, 6289-6293.

[32] D.K. Singh, L. Li, and T.D. Porter, Policosanol inhibits cholesterol synthesis in hepatoma cells by activation of AMP-kinase, J Pharmacol Ther, 318, 2006, 1020-1025.

[33] S. Oliaro, E. Calcio, S. Mantegna S, E. Giraudo, C. Meda, F. Viola F, et al: Regualtion of HMGCoA reductase by policosanol and octacosadienol, a new synthetic analogue of octacosanol, Lipids, 44, 2009, 907-16.

[34] S. Banerjee, S. Ghoshal, and T.D. Porter TD, Activation of AMP-kinase by Policosanol Requires Peroxisomal Metabolism, Lipids, 46, 2011, 311-21.

[35] R. Mas, G. Castaño, J. Illnait J, L. Fernández, J.C. Fernández, C. Alemán, et al, Effects of policosanol in patients with type II hypercholesterolemia and additional coronary risk factors, Clin Pharmacol Ther, 65, 1999, 439-447.

[36] H. Prat, O. Roman, and E. Pino E, Comparative effects of policosanol and two HMG-CoA reductase inhibitors on type II hypercholesterolemia, Rev Med Chil, 127, 1999, 286-494.

[37] I.P. Nikitin, N.V. Slepchenko, N.A. Gratsianskii, A.S. Nechaev, A.L. Syrkin, M.G. Poltavskaia, et al, Results of the multicenter controlled study of the hypolipidemic policosanol in Russia, Ter Arkh, 72, 2000, $7-10$.

[38] Y.Wang, Y. Ke, J. Wang, Y. Jiao, X. Zhao, N. Sun, et al, Efficacy and safety of policosanol and pravastatin in treatment of hyperlipidemia in Chinese patients, J New Drugs Clin Res,02, 2008, 124-29.

[39] M. Moonis, K. Kane, U. Schwiderski, B.W. Sandage, and M. Fisher M, HMG-CoA reductase inhibitors improve acute ischemic stroke outcome, Stroke, 36, 2005, 1298-300.

[40] M.J. Reeves, J. Warner, Z. Luo, and A.J. Mullard, Effect of pretreatment with statins on ischemic stroke outcomes, Stroke, 39, 2008, 1779-1785. 
Effects of policosanol on the recovery of ischemic stroke: a randomized controlled study

Table 1. Baseline characteristics of study population

\begin{tabular}{|c|c|c|c|}
\hline & Poli + AS $(n=46)$ & Pla + AS $(n=46)$ & Total $(n=92)$ \\
\hline Age $($ years $)(X \pm S D)$ & $66 \pm 10$ & $66 \pm 11$ & $66 \pm 10$ \\
\hline Body mass index $\left(\mathrm{kg} / \mathrm{m}^{2}\right)(X \pm S D)$ & $25.7 \pm 2.2$ & $26.1 \pm 2.0$ & $25.9 \pm 2.1$ \\
\hline Men, n (\%) & $25(54.3 \%)$ & $21(46.7 \%)$ & $46(50.0 \%)$ \\
\hline Women, n (\%) & $21(45.7 \%)$ & $25(54.3 \%)$ & $46(50.0 \%)$ \\
\hline 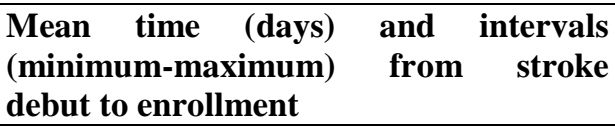 & $\begin{array}{c}15.3 \pm 5.6 \\
(6-30)\end{array}$ & $\begin{array}{c}16.8 \pm 7.7 \\
(2-35)\end{array}$ & $\begin{array}{c}16.1 \pm 6.7 \\
(2-35)\end{array}$ \\
\hline Modified Ranking Scale score & $2.9 \pm 0.5$ & $2.8 \pm 0.5$ & $2.9 \pm 0.5$ \\
\hline Salt-rich diet & $44(95.7 \%)$ & $45(97.8 \%)$ & $89(96.7 \%)$ \\
\hline Sedentary life & $46(100 \%)$ & $42(91.3 \%)$ & $88(95.6 \%)$ \\
\hline Hypertension & $44(95.7 \%)$ & $43(93.5 \%)$ & $87(94.6 \%)$ \\
\hline Overweight \& obesity & $30(65.2 \%)$ & $29(63.0 \%)$ & $59(64.1 \%)$ \\
\hline Smoking & $22(47.8 \%)$ & $20(43.5 \%)$ & $42(45.7 \%)$ \\
\hline Hypercholesterolemia & $8(17.4 \%)$ & $11(23.9 \%)$ & $19(20.6 \%)$ \\
\hline Diabetes & $5(10.9 \%)$ & $6(13.0 \%)$ & $11(12.0 \%)$ \\
\hline Coronary heart disease & $2(4.3 \%)$ & $4(8.7 \%)$ & $6(6.5 \%)$ \\
\hline \multicolumn{4}{|l|}{ Concomitant therapy ( $\square 5 \%$ ) } \\
\hline ACEI & $37(80.4 \%)$ & $30(65.2 \%)$ & $67(72.8 \%)$ \\
\hline
\end{tabular}

$(\mathrm{X} \pm \mathrm{SD})$ mean \pm standard deviation. ACEI angiotensing converting enzyme inhibitors All comparisons were not significant (Fisher's Exact Probability test) 
Effects of policosanol on the recovery of ischemic stroke: a randomized controlled study

Tabla 2. Distribution of cases according to the Modified Ranking Scale score (mRSs)

\begin{tabular}{|c|c|c|c|c|c|c|}
\hline \multirow{2}{*}{ mRSs values } & \multicolumn{2}{|c|}{ Baseline } & \multicolumn{2}{c|}{ 12 weeks } & \multicolumn{2}{c|}{ 24 weeks } \\
\cline { 2 - 7 } & Poli + AS & Pla + AS & Poli + AS & Pla + AS & Poli + AS & Pla + AS \\
\hline 0 & 0 & 0 & 0 & 0 & 2 & 0 \\
\hline 1 & 0 & 0 & $10^{++}$ & 0 & $30^{+++}$ & 7 \\
\hline $\mathbf{0}-\mathbf{1}$ & $\mathbf{0}$ & $\mathbf{0}$ & $\mathbf{1 0}^{++}$ & $\mathbf{0}$ & $\mathbf{3 2}^{++++}$ & $\mathbf{7}$ \\
\hline 2 & 7 & 13 & 27 & 19 & 11 & 19 \\
\hline $\mathbf{3}$ & 35 & 31 & $9^{+++}$ & 26 & $3^{+++}$ & 19 \\
\hline $\mathbf{4}$ & 4 & 2 & 0 & 1 & 0 & 1 \\
\hline $\mathbf{3}-\mathbf{4}$ & $\mathbf{3 9}$ & $\mathbf{3 3}$ & $\mathbf{9}^{+++}$ & $\mathbf{2 7}$ & $\mathbf{3}^{+++}$ & $\mathbf{2 0}$ \\
\hline
\end{tabular}

Data presented as $\mathrm{n}(\%)$, Poli policosanol, Pla placebo, AS aspirin

${ }^{+} \mathrm{p}<0.05,{ }^{++} \mathrm{p}<0.01,{ }^{++} \mathrm{p}<0.001,{ }^{++++} \mathrm{p}<0.0001$, Comparison with pla + AS

(Fischer's Exact Probabilty test)

Table 3. Effects on neurological recovery assessed through the modified Rankin Scale score $(X \pm S D)$

\begin{tabular}{|c|c|c|c|c|c|c|c|}
\hline $\begin{array}{c}\text { Treatment } \\
\text { s }\end{array}$ & Baseline & 6 weeks & 12 weeks & $\begin{array}{l}\text { Percent } \\
\text { changes }\end{array}$ & 18 weeks & 24 weeks & $\begin{array}{l}\text { Percent } \\
\text { changes }\end{array}$ \\
\hline Poli + AS & $2.9 \pm 0.5$ & $2.2 \pm 0.7^{+* * *}$ & $\begin{array}{c}2.0 \pm \\
0.6^{++^{* * *}}\end{array}$ & $-31.0^{++}$ & $\begin{array}{c}1.5 \pm \\
0.7^{++^{* * *}}\end{array}$ & $\begin{array}{c}1.3 \pm \\
0.7^{++* * *}\end{array}$ & $-55.2^{++}$ \\
\hline $\mathbf{P l a}+\mathbf{A S}$ & $2.8 \pm 0.5$ & $2.6 \pm 0.5$ & $2.5 \pm 0.5$ & -7.1 & $2.4 \pm 0.7^{*}$ & $2.3 \pm 0.8^{* *}$ & -17.9 \\
\hline
\end{tabular}

$(\mathrm{X} \pm \mathrm{SD})$ mean \pm standard deviation. $(\%)$, Poli policosanol, Pla placebo, AS aspirin

${ }^{*} \mathrm{p}<0.01,{ }^{* *} \mathrm{p}<0.001,{ }^{* * *} \mathrm{p}<0.00001$ Comparison with baseline (Wilcoxon test, Bonferroni adjustment) ${ }^{+} \mathrm{p}<0.01,{ }^{++} \mathrm{p}<0.00001$. Comparison with Pla + AS (Mann Whitney U test)

Table 4. Effects on the percent of platelet aggregation $(X \pm S M E)$

\begin{tabular}{|c|c|c|c|c|}
\hline Treatments & Baseline & 12 weeks & 24 weeks & Percent changes \\
\hline \multicolumn{5}{|c|}{ Arachidonic Acid (3 mmol/L) } \\
\hline Poli + AS & $43.2 \pm 5.7$ & $30.1 \pm 5.2^{*}$ & $25.5 \pm 4.5^{* *}$ & $\mathbf{- 4 1 . 0}$ \\
\hline Pla + AS & $39.0 \pm 5.4$ & $39.0 \pm 5.4$ & $37.5 \pm 5.2$ & $\mathbf{- 3 . 8}$ \\
\hline \multicolumn{3}{|c|}{ Adenosine phosphate (2 mmol/L) } \\
\hline Poli + AS & $42.0 \pm 3.7$ & $34.0 \pm 3.8^{*}$ & $31.6 \pm 3.6^{*}$ & $\mathbf{- 2 4 . 8}$ \\
\hline Pla + AS & $38.4 \pm 3.2$ & $42.8 \pm 3.6$ & $36.0 \pm 3.2$ & $\mathbf{- 6 . 2}$ \\
\hline
\end{tabular}

$\mathrm{X}$ mean, SME standard mean error, (\%), Poli policosanol, Pla placebo, AS aspirin $\mathrm{p}<0.05,{ }^{* *} \mathrm{p}<0.01$. Comparison with baseline (Wilcoxon test )

${ }^{+} \mathrm{p}<0.05$ Comparison with Pla + AS (Mann Whitney U test) 
Effects of policosanol on the recovery of ischemic stroke: a randomized controlled study

Table 5. Effects on lipid profile $(\mathrm{X} \pm \mathrm{SD})$

\begin{tabular}{|c|c|c|c|c|}
\hline Treatments & Baseline & 12 weeks & 24 weeks & Percent changes \\
\hline \multicolumn{5}{|c|}{ LDL-C (mmol/L) } \\
\hline Poli + AS & $3.41 \pm 1.07$ & $2.84 \pm 1.08^{* *+}$ & $2.54 \pm 1.28^{* * *+++}$ & $-25.5^{+++}$ \\
\hline Pla + AS & $3.26 \pm 0.96$ & $3.38 \pm 0.93$ & $3.43 \pm 0.89$ & 5.2 \\
\hline \multicolumn{5}{|c|}{ Total cholesterol total $(\mathrm{mmol} / \mathrm{L})$} \\
\hline Poli + AS & $5.80 \pm 1.25$ & $5.23 \pm 1.12^{* *++}$ & $5.08 \pm 1.30^{* * *+++}$ & $-12.4^{++}$ \\
\hline $\mathbf{P l a}+\mathbf{A S}$ & $5.78 \pm 1.20$ & $5.81 \pm 0.94$ & $5.85 \pm 0.99$ & 1.2 \\
\hline \multicolumn{5}{|c|}{ HDL-C (mmol/L) } \\
\hline Poli + AS & $1.52 \pm 0.30$ & $1.55 \pm 0.30$ & $1.68 \pm 0.27^{* * *}$ & 10.5 \\
\hline Pla + AS & $1.50 \pm 0.37$ & $1.51 \pm 0.41$ & $1.52 \pm 0.37$ & 1.3 \\
\hline \multicolumn{5}{|c|}{ Triglycerides $(\mathrm{mmol} / \mathrm{L})$} \\
\hline Poli + ASA & $1.84 \pm 0.96$ & $1.81 \pm 1.08$ & $1.70 \pm 1.03$ & -7.6 \\
\hline Pla + ASA & $1.88 \pm 0.90$ & $1.93 \pm 0.91$ & $1.87 \pm 0.86$ & -0.5 \\
\hline
\end{tabular}

$(\mathrm{X} \pm \mathrm{SD})$ mean \pm standard deviation. (\%), Poli policosanol, Pla placebo, AS aspirin

$\mathrm{p}<0.05,{ }^{* *} \mathrm{p}<0.01,{ }^{* * *} \mathrm{p}<0.001$. Comparison with baseline (Wilcoxon test)

${ }^{+} \mathrm{p}<0.05,{ }^{++} \mathrm{p}<0.01,{ }^{++} \mathrm{p}<0.001$. Comparison with Pla + AS (Mann Whitney U test)

Table 6. Effects on physical safety indicators $(X \pm S D)$

\begin{tabular}{|c|c|c|c|c|c|c|}
\hline Treatments & Baseline & 6 weeks & 12 weeks & 18 weeks & 24 weeks \\
\hline \multicolumn{5}{|c|}{ Bodyweight (kg) } \\
\hline Poli + AS & $\begin{array}{c}73.65 \pm \\
6.96\end{array}$ & $73.00 \pm 6.73$ & $72.41 \pm 6.81$ & $72.11 \pm 6.74$ & $72.04 \pm 6.36$ \\
\hline Pla + AS & $\begin{array}{c}74.87 \pm \\
9.08\end{array}$ & $74.89 \pm 9.32$ & $74.59 \pm 9.36$ & $74.43 \pm 9.14$ & $74.37 \pm 9.07$ \\
\hline \multicolumn{7}{|c|}{ Heart rate (beats/min) } \\
\hline Poli + AS & $\begin{array}{c}77.57 \pm \\
5.71\end{array}$ & $77.13 \pm 5.34$ & $77.98 \pm 4.28$ & $77.93 \pm 4.07$ & $77.85 \pm 4.47$ \\
\hline Pla + AS & $\begin{array}{c}78.80 \pm \\
6.50\end{array}$ & $77.22 \pm 5.36$ & $78.39 \pm 4.48$ & $77.87 \pm 4.97$ & $78.30 \pm 5.23$ \\
\hline \multicolumn{7}{|c|}{ Diastolic blood pressure (mm Hg) } \\
\hline Poli + AS & $\begin{array}{c}83.70 \pm \\
5.21\end{array}$ & $80.87 \pm 4.75$ & $79.67 \pm 4.76$ & $79.35 \pm 4.55$ & $78.70 \pm 4.27$ \\
\hline Pla + AS & $\begin{array}{c}84.46 \pm \\
5.08\end{array}$ & $81.46 \pm 4.67$ & $80.54 \pm 3.02$ & $79.57 \pm 4.57$ & $79.04 \pm 4.12$ \\
\hline \multicolumn{7}{|c|}{ Sistolic blood pressure (mm Hg) } \\
\hline Poli + AS & $\begin{array}{c}132.72 \pm \\
9.29\end{array}$ & $126.85 \pm 7.41^{+}$ & $124.57 \pm 6.74$ & $123.26 \pm 5.98^{+}$ & $123.04 \pm 5.52^{+}$ \\
\hline Pla + AS & $\begin{array}{c}134.46 \pm \\
8.83\end{array}$ & $130.76 \pm 5.77$ & $126.85 \pm 5.81$ & $127.07 \pm 4.78$ & $128.09 \pm 8.99$ \\
\hline
\end{tabular}

$(\mathrm{X} \pm \mathrm{SD})$ mean \pm standard deviation. $(\%)$, Poli policosanol, Pla placebo, AS aspirin ${ }^{+} \mathrm{p}<0.01$ Comparisons with pla + AS (Analysis of Variance) 
Table 7. Effects on safety blood biochemistry indicators $(X \pm S D)$

\begin{tabular}{|c|c|c|c|}
\hline Treatments & Baseline & 12 weeks & 24 weeks \\
\hline \multicolumn{4}{|c|}{$\operatorname{ALT}(\mathbf{U I})$} \\
\hline Poli + AS & $21.72 \pm 9.22$ & $20.11 \pm 8.05$ & $19.04 \pm 8.45^{+}$ \\
\hline $\mathbf{P l a}+\mathbf{A S}$ & $22.85 \pm 14.30$ & $20.87 \pm 9.71$ & $23.41 \pm 11.73$ \\
\hline \multicolumn{4}{|c|}{ AST (UI) } \\
\hline Poli + AS & $22.85 \pm 6.88$ & $25.15 \pm 6.65$ & $23.63 \pm 7.83$ \\
\hline $\mathbf{P l a}+\mathbf{A S}$ & $24.44 \pm 10.60$ & $22.26 \pm 7.72$ & $24.15 \pm 8.44$ \\
\hline \multicolumn{4}{|c|}{ GGT (UI) } \\
\hline Poli + AS & $34.19 \pm 17.52$ & $35.07 \pm 19.39$ & $34.80 \pm 21.21$ \\
\hline $\mathbf{P l a}+\mathbf{A S}$ & $36.74 \pm 20.35$ & $36.34 \pm 19.08$ & $34.38 \pm 17.93$ \\
\hline \multicolumn{4}{|c|}{ Glucose $(\mathrm{mmol} / \mathrm{L})$} \\
\hline Poli + AS & $4.55 \pm 1.20$ & $4.77 \pm 1.45$ & $4.71 \pm 1.35$ \\
\hline $\mathbf{P l a}+\mathbf{A S}$ & $4.61 \pm 1.64$ & $4.74 \pm 1.43$ & $4.87 \pm 1.40$ \\
\hline \multicolumn{4}{|c|}{ Creatinine $(\mu \mathrm{mol} / \mathrm{L})$} \\
\hline Poli + AS & $92.82 \pm 27.83$ & $90.42 \pm 31.44$ & $94.26 \pm 29.32$ \\
\hline $\mathbf{P l a}+\mathbf{A S}$ & $91.89 \pm 45.15$ & $95.85 \pm 40.03$ & $97.85 \pm 45.22$ \\
\hline
\end{tabular}

$(\mathrm{X} \pm \mathrm{SD})$ mean \pm standard deviation. (\%), Poli policosanol, Pla placebo, AS aspirin ALT alanin amino transferase, AST aspartate amino transferase, GGT $\gamma$ glutamyl transpeptidase ${ }^{+} \mathrm{p}<0.05$, Comparisons with pla + AS (Analysis of Variance) 